\title{
Densely Granulated Lactotroph Adenoma
}

National Cancer Institute

\section{Source}

National Cancer Institute. Densely Granulated Lactotroph Adenoma. NCI Thesaurus. Code C45931.

A rare prolactin producing pituitary gland adenoma composed of acidophilic cells with many large secretory granules. The endoplasmic reticulum is not as abundant as in the sparsely granulated subtype. 